\title{
CONSUMER ADOPTION OF FAST-FASHION, DIFFERENCES OF PERCEPTIONS, AND THE ROLE OF MOTIVATIONS ACROSS THE ADOPTION GROUPS
}

\author{
Nazan Okur* \\ Istanbul Technical University, Faculty of Textile Technologies and Design, Inonu Cad. No. 65 34437, Gumussuyu Beyoglu, Istanbul, Turkey \\ *Corresponding author. E-mail: okurn@itu.edu.tr
}

\begin{abstract}
:
The purpose of this study was to determine the adoption groups of the fast-fashion consumers, evaluate the consumers' perceptions of the fast-fashion in different groups, and model the role of "social or status image", "uniqueness", and "conformity" on the level of fast-fashion consumer adoption. The consumer adoption groups were determined as "innovators", "early adopters", "early majority", "late majority", and "laggards" by using a domainspecific innovativeness (DSI) scale. Consumers' perceptions of fast-fashion were evaluated from cognitive and emotional aspects and the differences across the consumer groups were investigated by using Kruskal-Wallis test and Mann-Whitney U test. The roles of "social or status image", "uniqueness", and "conformity" on consumer groups were modeled by using ordinal logistic regression analysis. As a result of the research, consumers' perceptions of fast-fashion were found to vary across different consumer adoption groups in terms of "being in-style products", "expressing self-image", "imitating the luxury fashion products", and "frequent renewal of the collections". Further, the findings revealed that the probabilistic relationship between different levels of consumer adoption based on innovativeness could be modeled based on the motivations of "social or status image" and "uniqueness".
\end{abstract}

\section{Keywords:}

Fast-fashion, consumer adoption groups, innovativeness, fast-fashion perception, motivation, logistic regression, ordinal response

\section{Introduction}

The fast-fashion market is expected to reach US\$ 38 billion in 2023 from US $\$ 35$ billion in 2019 despite registering a decline in 2020 due to the Covid-19 pandemic [1]. This shows that the demand for fast-fashion products is increasing worldwide. Fast-fashion is a strategy that is driven by the demand of the consumers, and the fast-changing and increasing consumer demand can be responded to efficiently only through aan appropriate understanding of the consumers' degree of adoption to fast-fashion products. Differentiating between consumers' perceptions of fast-fashion and investigating the role of motivations make them adopt fast-fashion depending on the degree of adoption that can contribute to the development of the right strategies for the market.

Fast-fashion consumption is adopted by the consumers since it is enjoyable, presents a tool that conveys the identity of the individual to the world, and enables the determination of social groups; therefore it provides experiences having cognitive and emotional aspects [2]. From the cognitive perspective of consumers, fast-fashion products are low-priced and in-style products; they have an acceptable quality level and collections are renewed frequently [2, 3]. From the emotional perspective, consumers associate fast-fashion products with opportunities to socialize, express their self-perception images, and act differently during purchase [2, 3]. Besides, they also have good experience using luxury fashion products, since the fast-fashion products are offered by brands that mimic luxury fashion brands [2, 4].

The tendency of consumers to adopt and to purchase new fast-fashion or any fashion products is related to the degree of innovativeness in such products. Rogers defined innovativeness in his time-of-adoption method as "the degree to which an individual is relatively earlier in adopting new ideas than the other members of his/her social system" [5]. Within this context, consumer innovativeness is precisely related to the adoption of the consumers to the new products and services [6]. On the basis of innovativeness, different consumer adoption groups were identified with their percentages (rates of adoption) in Rogers' Diffusion of Innovations theory [7]. Although originally applied in non-fashion fields of study, this approach was later applied in fashion adoption researches. On the other hand, no specific application was conducted for investigating the adoption of fast-fashion consumers. However, considering the fast-fashion concept and product features, differences can be expected to arise in the rate of adoption and cycle of adoption. 
The purpose of this study was to determine the fast-fashion consumer adoption groups based on their innovativeness, investigate the differences across the adoption groups in terms of their perception of fast-fashion, and model the role of social or status image, uniqueness, and conformity, which are the motivations of the consumers that make them adopt fastfashion products; this motivation can be postulated to arise in consumers as a result of their willingness to inculcate greater innovativeness in their lives [8]. In doing so, the study aimed to provide valuable insights for understanding the fast-fashion consumer market.

\section{Literature review}

Rogers proposed the time-of-adoption method to measure the innovativeness and categorized individuals into five adoption categories as "innovators", "early adopters/opinion leaders", "early majority", "late majority", and "laggards". Innovators are the earliest in adoption as compared to other members of the system. Early adopters/opinion leaders are the individuals that have the highest degree of opinion leadership among the consumer groups [7]. Fashion opinion leadership is the ability to deliver information relating to a new fashion or product in a way that influences the subsequent purchasers to accept or reject the product [9]. The early majority denotes the individuals who adopt just before the average member of the system, whereas the late majority does not adopt until most others in their system have already done so. Laggards, on the other hand, are the last consumers who adopt innovation in society. Rogers also showed the quantitative distribution of the consumers in the adoption cycle, which is also called the Diffusion of Innovations theory [7]. Rogers' measurement of innovativeness and fashion adoption categories also formed a base for subsequent studies, in which these categories showed a slight variation compared to those in Rogers' study. Baumgarten explored the overlap between opinion leaders and early adopters and identified a group called "innovator communicators", who are both innovators and opinion leaders. The author then investigated the process of fashion adoption by "opinion leaders", "early adopters", and "innovative communicators" [10]. Hirschman and Adcock specified four adopter categories: "innovative communicators", "opinion leaders", "innovators", and "general population", by using the fashion opinion leadership scale. In this categorization, the scoring of the consumers on innovativeness and opinion leadership was evaluated. According to this scoring, "innovative communicators" are those individuals who score high on both innovativeness and opinion leadership. "Opinion leaders" are individuals who score high on opinion leadership, but not on innovativeness. The "innovators" are the individuals who score high on innovativeness, but not on opinion leadership. Lastly, "general population", which is also called "fashion followers", includes the ones who score neither on innovativeness nor on opinion leadership [11]. Workman and Lee proposed a model for fashion adoption and identified four groups, which are "consumer change agents", "early adopters", "late adopters", and "reluctant adopters" [12].
Based on these categorizations, researchers identified the differences between fashion consumer groups in terms of their perspective regarding the centrality of visual product aesthetics and their need for tactile feedback [13], their use of label information in ratings of clothing quality and fashionability [14], their sensation seeking and clothing individuality [15], and their propensity toward boredom [16]. Consumers' need for uniqueness and attention to social comparison information was found to be positively related to fashion opinion leadership [17]. Using the fashion opinion leadership inventory scale, Schrank and Gilmore examined the relationship between innovativeness, social insecurity, conformity, clothing interest, and socioeconomic level [18]. Motivational factors of different consumer groups were further investigated by Cholachatpinyo et al., who focused on the socialization and differentiation forces in the selection of clothing and fashion items, and explored their impacts on fashion innovators and fashion followers. The categorization of consumers was adapted from Rogers' fashion adoption categories, and was somewhat narrowed [19]. Jordaan et al. [20] measured consumer innovativeness by using the domain-specific innovativeness (DSI) scale developed by Goldsmith and Hofacker [21], instead of using Rogers' time-of-adoption method, since it is difficult to know the exact time of the introduction and the purchase of a new product in a specific market. Venter et al. investigated the influence of fashion consciousness, the need for uniqueness, susceptibility to interpersonal influence, collectivism/individualism, and masculinity/femininity on fashion adoption [22]. Workman et al. identified the differences between consumer groups in their need for uniqueness [13, 23]. The abovementioned studies-reviewed for the motivational factors of different consumer groups in relation to their proclivities toward fashion innovativeness and fashion adoption-mostly investigated the consumer need for expressing their uniqueness and individuality to be different from other individuals, thereafter the need for belonging to a social group and display conformity, and finally for socialization concerns.

While almost all of the studies focused on the investigation of the behavior of different consumer groups for general fashion consumption, a very limited number of studies specifically dealt with the categorization of fast-fashion consumers and their motivations for adoption of innovation. Byun and Sternquist investigated the importance of willingness for the innovativeness for the fast-fashion consumers and argued that fast-fashion consumers enjoy experiencing the quick launch of fast-fashion products and frequent changes in fast-fashion cycles [24]. In the only study on association of fast-fashion consumers with the adoption categories, Barnes explored the role relations between fast-fashion and consumer groups play in contributing to the formulation of an understanding of the needs and demands of consumers [25]. Saricam and Erdumlu investigated the consumer behavior specifically about fast-fashion products using three motivational factors, namely conformity, uniqueness, and social or status image. In the study, the motivational factors were related to the consumers' willingness for innovativeness [8]. Based on the literature reviewed, there is no comprehensive study that measures the innovativeness of the consumers, categorizes the consumers based on innovativeness, and explores the perceptions and 
motivations in different adoption categories specifically in the field fast-fashion. Considering the limitations and deficiencies observed in the previous studies, this article addressed this gap in the literature and attempted to contribute to a better understanding of fast-fashion consumers.

\section{Materials and methods}

\subsection{Data collection and questionnaire}

The data were obtained through an online survey conducted from April to May, 2015 among a sample from the population of fast-fashion consumers in Turkey. The survey questionnaire consisted of four parts. In the first part, the sociodemographic characteristics and the purchasing habits of the participants were asked. In the second part, the DSI on a 5 point-Likert scale developed by Goldsmith and Hofacker [21] was used to categorize the participants. In the third part, the participants were required to rate their perceptions of fast-fashion including nine aspects by using a 5-point Likert scale. The aspects were modified from the literature $[2-4,26]$ pertaining to the fastfashion products as being "in-style products", "low-priced", "having acceptable level of quality", "frequent renewal of collections", "opportunities towards socialization", "association with brand names", "imitating the luxury fashion products", "expressing self-image", and "allowing to act differently during purchasing". In the fourth part, 16 items were used to explore the role of conformity, social or status image, and uniqueness on different consumer adoption groups with 4, 3, and 3 items adopted from studies of Eastman, Goldsmith and Flynn [27], Tian, Bearden and Hunter [28] and Goldsmith and Flynn [6], respectively.

\subsection{Data analysis}

In the present study, the responses of 244 participants were analyzed. The participants were first categorized based on the adoption groups proposed by Rogers [7] into "innovators", "early adopters", "early majority", "late majority" and "laggards". The questions were coded so that a high score reflected higher levels of innovativeness. The responses of the six questions were summed up and provided a DSI score. Accordingly, fast-fashion consumer groups were identified as "innovators", "early adopters", "early majority", "late majority", and "laggards" corresponding to the domain-specific scores of (30-26), (25-21), (20-16), (15-11), and (10-6), respectively.

The differences in the perceptions of fast-fashion among different consumer groups were investigated by using the nonparametric Kruskal--Wallis test and Mann- Whitney $U$ test by using IBM SPSS, v.23.0 statistical software at a $90 \%$ confidence interval.

$$
\begin{gathered}
j=1, \ldots \ldots ., \mathrm{J}-1 \\
\ln \left(\frac{P(Y \leq j \mid x}{P(Y>j \mid x}\right)=\alpha_{j}+\left(\beta_{1} X_{1}+\beta_{2} X_{2}+\ldots \beta_{p} X_{p}\right)
\end{gathered}
$$

To model the relationship between the consumer groups and influential motivational factors, the ordinal logistic regression method was used. Logistic regression for the ordinal response variable, which is also called as proportional odds model, was used to assess the influence of statistically significant explanatory variables on consumer groups using XLSTAT and IBM SPSS, v. ersion 23.0 software at a 95\% confidence interval. The proportional odds model [29] can be defined [29] as represented in Eq. (1), as follows:

$$
\ln \left(\frac{P(Y \leq j \mid x}{P(Y>j \mid x}\right)=\alpha_{j}+\left(\beta_{1} X_{1}+\beta_{2} X_{2}+\ldots \beta_{p} X_{p}\right) \ldots j=1, \ldots \ldots \ldots, J-1
$$

Within this model, $j$ is the number of response levels of the response variable innovativeness, which corresponds to consumer groups, and $p$ is the number of the explanatory variables, which corresponds to the motivational factors, "Conformity", "Social or status image", and "Uniqueness". The probability of an equal or smaller response $Y \leq j$ is compared with the probability of a larger response, $Y>j$ where $j$ is the rank of the ordinal responses. $P(Y \leq j \mid x)$ is the cumulative probability for response level $j$ when the explanatory variables take value $x$ and a cumulative probability for $Y$ is the probability that $Y$ falls at or below a particular point. Consequently, $j-1$ linear predictors are obtained for comparing the response levels. The $\left\{\mathrm{a}_{i}\right\}$ are called cut point (intercept) parameters and they are non-decreasing in $j$ [29].

Proportional odds mean that the effect of any explanatory variable for each response level must be consistent, or have parallel slopes, across all levels of the response. Therefore, as the first step in ordinal logistic regression, the test of parallel lines was done for evaluating the assumption that the relationships between the explanatory variables and the logits are the same for all linear prediction equations [30].

The significance of the explanatory variables was tested by using the likelihood ratio test, the Wald test, and the score test. In the likelihood ratio test, the model without any explanatory variable (baseline model) is compared against the model with all the explanatory variables (final model). The Wald test compares the maximum likelihood estimate of the slope parameter $\beta i$, to an estimate of its standard error [31]. The score test is a test of the null hypothesis in which the corresponding coefficients are located between two binary coefficients [32].

The relationship between the explanatory variables and the response levels was evaluated by calculating pseudo $R^{2}$ values. However, in the logistic regression analysis, pseudo $R^{2}$ is difficult to interpret. Instead, proportional odds ratios are more likely to be more useful [33-35]. Therefore, odds ratios, which represent the constant effect of an explanatory variable on the likelihood that one outcome will occur, were calculated. Finally, linear predictor equations, comparing the influences of the consumer groups on the adoption cycle that is based on innovativeness, were proposed. 


\section{Results}

\subsection{Profiles of consumer adoption groups}

Table 1 shows the sociodemographic profile and purchasing habits of the participants in relation to consumer adoption groups. The proportion of the participants in each consumer group was found to be consistent with the innovation/adoption curve of Rogers [7]; in this item in the literature, it has been demonstrated that the fashion is accepted and diffuses from innovators to early adopters, and then moves into a peak stage where a larger number of consumers begin to adopt the fashion. Subsequently, the diffusion process moves to a decline stage, and the number of adopters decreases.

Figure 1. demonstrates the adoption cycle of Rogers' model and the fast-fashion consumers grouped in the present study. In Rogers' model, innovators covered $2.5 \%$ of the population;

Table 1. Sociodemographic profile of the participants with regard to consumer groups

\begin{tabular}{|c|c|c|c|c|c|c|c|c|c|c|c|}
\hline & & \multicolumn{2}{|c|}{ Laggards } & \multicolumn{2}{|c|}{ Late majority } & \multicolumn{2}{|c|}{$\begin{array}{c}\text { Early } \\
\text { majority }\end{array}$} & \multicolumn{2}{|c|}{$\begin{array}{c}\text { Early } \\
\text { adopters }\end{array}$} & \multicolumn{2}{|c|}{ Innovators } \\
\hline & & Freq. & $\%$ & Freq. & $\%$ & Freq. & $\%$ & Freq. & $\%$ & Freq. & $\%$ \\
\hline \multirow{3}{*}{ Gender } & Female & 5 & 31 & 42 & 48 & 55 & 59 & 21 & 62 & 10 & 77 \\
\hline & Male & 11 & 69 & 46 & 52 & 38 & 41 & 13 & 38 & 3 & 23 \\
\hline & Total & 16 & 100 & 88 & 100 & 93 & 100 & 34 & 100 & 13 & 100 \\
\hline \multirow{5}{*}{ Age (Years) } & $18-23$ & 10 & 63 & 61 & 69 & 50 & 54 & 16 & 47 & 5 & 38 \\
\hline & 24-29 & 6 & 38 & 20 & 23 & 30 & 32 & 14 & 41 & 7 & 54 \\
\hline & $30-35$ & 0 & 0 & 5 & 6 & 8 & 9 & 2 & 6 & 1 & 8 \\
\hline & 36 and above & 0 & 0 & 2 & 2 & 5 & 5 & 2 & 6 & 0 & 0 \\
\hline & Total & 16 & 100 & 88 & 100 & 93 & 100 & 34 & 100 & 13 & 100 \\
\hline \multirow{4}{*}{ Education } & High school and below & 1 & 6 & 2 & 2 & 7 & 8 & 2 & 6 & 0 & 0 \\
\hline & Undergraduate & 14 & 88 & 78 & 89 & 79 & 85 & 28 & 82 & 10 & 77 \\
\hline & Graduate & 1 & 6 & 8 & 9 & 7 & 8 & 4 & 12 & 3 & 23 \\
\hline & Total & 16 & 100 & 88 & 100 & 93 & 100 & 34 & 100 & 13 & 100 \\
\hline \multirow{5}{*}{$\begin{array}{l}\text { Working } \\
\text { position }\end{array}$} & Non-worker/retired & 0 & 0 & 2 & 2 & 6 & 6 & 0 & 0 & 0 & 0 \\
\hline & Student & 13 & 81 & 65 & 74 & 58 & 62 & 21 & 62 & 9 & 69 \\
\hline & Employee & 3 & 19 & 20 & 23 & 29 & 31 & 11 & 32 & 3 & 23 \\
\hline & Senior manager & 0 & 0 & 1 & 1 & 0 & 0 & 2 & 6 & 1 & 8 \\
\hline & Total & 16 & 100 & 88 & 100 & 93 & 100 & 34 & 100 & 13 & 100 \\
\hline \multirow{6}{*}{$\begin{array}{l}\text { Income } \\
\text { level }\end{array}$} & Low & 10 & 63 & 45 & 51 & 31 & 33 & 13 & 38 & 5 & 38 \\
\hline & Low to moderate & 1 & 6 & 19 & 22 & 31 & 33 & 10 & 29 & 3 & 23 \\
\hline & Moderate & 3 & 19 & 12 & 14 & 13 & 14 & 8 & 24 & 2 & 15 \\
\hline & Moderate to high & 2 & 13 & 7 & 8 & 14 & 15 & 2 & 6 & 2 & 15 \\
\hline & High & 0 & 0 & 5 & 6 & 4 & 4 & 1 & 3 & 1 & 8 \\
\hline & Total & 16 & 100 & 88 & 100 & 93 & 100 & 34 & 100 & 13 & 100 \\
\hline \multirow{6}{*}{$\begin{array}{l}\text { Purchase } \\
\text { frequency }\end{array}$} & Twice a week & 0 & 0 & 9 & 10 & 1 & 1 & 9 & 26 & 1 & 8 \\
\hline & Once a week & 5 & 31 & 6 & 7 & 28 & 30 & 7 & 21 & 4 & 31 \\
\hline & Twice a month & 2 & 13 & 32 & 36 & 39 & 42 & 9 & 26 & 7 & 54 \\
\hline & Once a month & 5 & 31 & 15 & 17 & 12 & 13 & 4 & 12 & 0 & 0 \\
\hline & Once in 2 months & 4 & 25 & 26 & 30 & 13 & 14 & 5 & 15 & 1 & 8 \\
\hline & Total & 16 & 100 & 88 & 100 & 93 & 100 & 34 & 100 & 13 & 100 \\
\hline \multirow{7}{*}{$\begin{array}{c}\text { Purchase } \\
\text { expense } \\
\text { ratio }\end{array}$} & Below 10\% & 3 & 19 & 18 & 20 & 7 & 8 & 5 & 15 & 0 & 0 \\
\hline & $11-20 \%$ & 7 & 44 & 33 & 38 & 35 & 38 & 11 & 32 & 3 & 23 \\
\hline & $21-30 \%$ & 5 & 31 & 23 & 26 & 33 & 35 & 9 & 26 & 4 & 31 \\
\hline & $31-40 \%$ & 1 & 6 & 8 & 9 & 11 & 12 & 4 & 12 & 3 & 23 \\
\hline & $41-50 \%$ & 0 & 0 & 4 & 5 & 4 & 4 & 4 & 12 & 1 & 8 \\
\hline & Above $50 \%$ & 0 & 0 & 2 & 2 & 3 & 3 & 1 & 3 & 2 & 15 \\
\hline & Total & 16 & 100 & 88 & 100 & 93 & 100 & 34 & 100 & 13 & 100 \\
\hline
\end{tabular}


on the other hand, early adopters, early majority, late majority, and laggards covered $13.5 \%, 34.0 \%, 34.0 \%$, and $16.0 \%$ of the population, respectively [7]. In the present study, however, the ratios of innovators, early adopters, early majority, late majority, and laggards corresponded to $5.3 \%, 13.9 \%, 38.1 \%$, $36.1 \%$, and $6.6 \%$ of the participants, respectively. The results revealed that the first three fast-fashion consumer groups ( i.e., innovators, early adopters, and early majority) covered more of the population when compared to the percentages of the population covered by the same categories in Rogers' adoption curve. This can be attributed to the fact that the features of fast-fashion products satisfy the demands of the innovators and early adopters [24]. Moreover, the percentage of the innovators was greater, whereas that of the laggards was lower for the fast-fashion consumers when compared to Rogers' model. It was also observed that the peak category for the fashion consumers belonged to the early majority with $38.1 \%$, whereas, in Rogers' model, the peak percentage again belonged to the early majority, though it was lower compared to the fast-fashion consumers and was equal to the percentage of the late majority. The higher rate of adoption of fast-fashion consumers is compatible with the short life cycle of fast-fashion products.

With regard to gender, it can be noticed that almost threequarters of the innovators were female, whereas around $70 \%$ of the laggards were male (Table 1). As the fashion innovativeness of the participants increased, the number of females also increased. Another remarkable point is that the ratio of the participants with a "moderate to high" and "high" level of income was $23 \%$ for innovators, whereas other consumer groups had a lower ratio in terms of those income levels. Likewise, $92 \%$ of the innovators purchased clothes more than once a month, which was the highest percentage among all consumer groups. Concerning the purchase expense ratio, the ratio of the participants who allocated above $30 \%$ of their income increased as the fashion innovativeness increased. It can be concluded that female consumers are more innovative in the fast-fashion market. Moreover, as consumers' level of innovativeness increases, there are more consumers at the postgraduate level, the level of income increases, the frequency of clothing for shopping rises, and the budget allocated for shopping for clothing increases.

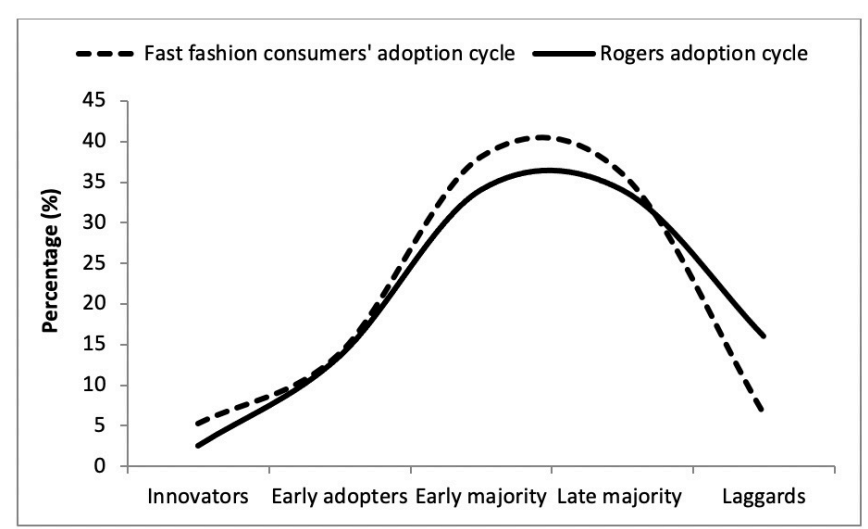

\subsection{Perceptions of fast-fashion across the consumer adoption groups}

According to the Kruskal--Wallis test results, the perceptions of fast-fashion products including "being in-style products", "expressing the self-image", "imitating the luxury fashion products", and "frequent renewal of collections", differed significantly according to the consumer groups $(p<0.10)$. These results are consistent with those in previous studies. Fashion innovators were defined as consumers who are more interested in fashion and shopping and use clothing to express their individuality $[14,15,18,23,36]$. In addition to the primary motivation of feeling different, expressing their self-image through usage of innovative apparel was a concern for the fashion innovators. Further, fast-fashion is identified as "allowing dreams of luxury to come true" [4]. The differences among the perception of the fast-fashion products "imitating the luxury fashion" among the consumer groups can be attributed to the fact that high fashion innovators have a willingness to possess unique luxury products, and fashion innovators are the key luxury fashion consumer group [37]. Finally and importantly, high fashion innovators are the earliest consumers for innovations [38].

When all consumer groups were compared in pairs by using the Mann--Whitney $U$ - test in terms of consumers' perceptions, it was observed that the fashion innovators' perception of fastfashion products in regard to "imitating the luxury fashion products" differed from the perceptions corresponding to all other consumer groups. The perception of the laggards towards fast-fashion products in terms of "frequent renewal of collections" was found to be significantly different from the other consumer groups. In other words, frequent renewal of collections was of no concern to laggards. Moreover, both the consumer groups of the "late majority" and the "laggards" did not perceive fast-fashion as a tool for "expressing the selfimage". No significant difference was observed between other paired comparisons of consumer groups.

\subsection{Modeling of the motivations of adoption for consumer adoption groups}

The three explanatory variables ("conformity", "social or status image", and "uniqueness") were used as explanatory variables in the ordinal logistic regression analysis. These three explanatory variables were used to obtain linear prediction equations that compared the categorized response variable, which, in the present study, was the influence of the consumer groups on the adoption cycle that is based on innovativeness.

The chi-square value obtained as the result of the test of parallel lines, which evaluated the assumption that the relationships between the explanatory variables and the logits were the same for all the logits, was $11.281(\mathrm{df}=9)$ with a $p$-value of $0.257(>0.05)$. This means that the categories of the response variable, which was the influence of the consumer groups on the adoption cycle that is based on innovativeness, were parallel with each other. In other words, the coefficients

Figure 1. Comparison of fast-fashion consumers' adoption cycle and Roger's adoption cycle. 
belonging to the explanatory variables (Estimate $(b)$ values in Table 3 ) were equal for each consumer category.

The model-fitting information regarding the likelihood ratio test, the Wald's test, and the score test are given in Table 2. The chi-square values of the Llikelihood ratio test, the Wald's test, and the score test were obtained as $55.577(\mathrm{df}=3$ ), 50.996 ( $d f=3)$, and $55.345(d f=3)$, respectively, with the $p$-values of 0.000 . Thus, the explanatory variables, as a group, contributed significantly to the prediction of the response variable innovativeness.

In the next step, the effect and the significance of the explanatory variables were evaluated. According to the results of the final ordinal logistic regression model employed with three explanatory variables, the $p$-values of $0.000,0.000$, and 0.437 for the explanatory variable 1 (social or status image), the explanatory variable 2 (uniqueness), and the explanatory variable 3 (conformity), respectively, were obtained. This indicated that two explanatory variables, "social or status image" and "uniqueness", were significant on the influence of the consumer groups on the adoption cycle that is based on innovativeness, confirming the earlier findings in the literature [8]. The significant relationship between "social or status image" and fashion innovativeness can be attributed to the fact that consumers who are willing to express their social or status image through their clothing are adapting faster to new trends, styles, or fashion products. Watson and Yan stated that the unique style characteristics of fast-fashion should be the complement of the self-image [39]. They also indicated that fast-fashion consumers enjoy purchasing trendy products at affordable prices; this finding was confirmed by Bagwell and Bernheim, who highlightedemphasized that those consumers having the willingness to seem wealthy purchase a large number of products at low prices [40]. The other significant motivation underlying fashion innovativeness was "uniqueness". Previous studies have shown that to look unique, fast-fashion consumers prefer purchasing scarce products that are produced in low quantities [4]. Moreover, Jordaan and Simpson concluded that $25.8 \%$ of fashion innovativeness can be explained by the variation in the need for fashion uniqueness [20]. The insignificance of "conformity" was attributed to the fact that the individuals who prefer fast-fashion products did not face a need to display conformity with others [8]. Innovator consumers are likely to throw away their clothing to avoid conformity [41]. As can be seen in the fast-fashion adoption curve, fast-fashion consumers are more innovative, and differentiation motivations (such as the need for uniqueness and expression of their social or status image) were influential rather than socialization forces (such as being in conformity with their social circle) [19].

To assess the model for possible numerical errors, $95 \%$ of the confidence intervals were checked. For the significant explanatory variables, smaller confidence intervals suggest greater precision of the variable. Since the 95\% confidence intervals for two significant variables were found to be 0.507 and 0.491 , which are lower than 1 , a lack of significance was not expected [31, 42]. The parameter estimates are shown in Table 3. As there were five consumer groups, four intercepts were obtained.

The proportional odds models, i.e., linear predictor equations, comparing the influences of the consumer groups on the adoption cycle that is based on innovativeness, are given below. Since there were five consumer groups, four linear prediction equations (Eqs (2)-(5)) were obtained.

Table 2. Model fitting information

\begin{tabular}{|c|c|c|c|c|c|c|c|c|c|}
\hline \multirow[b]{2}{*}{ Model } & \multicolumn{3}{|c|}{ Likelihood ratio test } & \multicolumn{3}{|c|}{ Wald's test } & \multicolumn{3}{|c|}{ Score test } \\
\hline & Chi-square & df & Sig. & Chi-square & df & Sig. & Chi-square & df & Sig. \\
\hline Fitted model & 55.577 & 3 & 0.000 & 50.996 & 3 & 0.000 & 55.345 & 3 & 0.000 \\
\hline
\end{tabular}

Table 3. Parameter estimates

\begin{tabular}{|c|c|c|c|c|c|c|c|c|}
\hline & \multirow{2}{*}{ Estimate $(\beta)$} & \multirow{2}{*}{ Wald } & \multirow{2}{*}{$\begin{array}{l}\text { Standard } \\
\text { Error }\end{array}$} & \multirow{2}{*}{ df. } & \multirow{2}{*}{ Sig. } & \multirow{2}{*}{$\begin{array}{l}\text { Odds ratio } \\
(\operatorname{Exp}(\beta))\end{array}$} & \multicolumn{2}{|c|}{$\begin{array}{c}95 \% \text { Confidence } \\
\text { interval }\end{array}$} \\
\hline & & & & & & & $\begin{array}{l}\text { Lower } \\
\text { bound }\end{array}$ & $\begin{array}{l}\text { Upper } \\
\text { bound }\end{array}$ \\
\hline Intercept 1 & -3.032 & 120.411 & 0.276 & 1 & 0.000 & & -3.573 & -2.490 \\
\hline Intercept 2 & -0.333 & 5.624 & 0.140 & 1 & 0.018 & & -0.608 & -0.058 \\
\hline Intercept 3 & 1.673 & 88.325 & 0.178 & 1 & 0.000 & & 1.324 & 2.022 \\
\hline Intercept 4 & 3.239 & 117.908 & 0.298 & 1 & 0.000 & & 2.654 & 3.823 \\
\hline $\begin{array}{l}\text { Variable } 1 \text { (social } \\
\text { or status image) }\end{array}$ & 0.790 & 37.272 & 0.129 & 1 & 0.000 & 2.203 & 0.537 & 1.044 \\
\hline $\begin{array}{c}\text { Variable } 2 \\
\text { (uniqueness) }\end{array}$ & 0.550 & 19.294 & 0.125 & 1 & 0.000 & 1.733 & 0.305 & 0.796 \\
\hline $\begin{array}{l}\text { Variable } 3 \\
\text { (conformity) }\end{array}$ & 0.093 & 0.603 & 0.120 & 1 & 0.437 & 1.097 & -0.142 & 0.329 \\
\hline
\end{tabular}




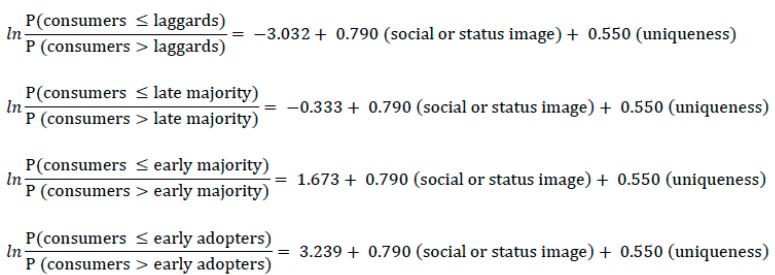

The coefficient estimates of the explanatory variable "social or status image", with a value of 0.790 , showed that it had the most significant relationship with the consumer category, followed by "uniqueness" with the coefficient estimate value of 0.550 .

Three different pseudo $R^{2}$ summary statistics that can be used to assess model fit were obtained as follows: Cox and Snell, 0.203; Nagelkerke, 0.218; and McFadden, 0.084. The pseudo $R^{2}$ summary statistics in the present study would be considered somewhat weak. Instead, proportional odds ratios were calculated to understand the effect of the variables on the categories of the response variable innovativeness. The $\operatorname{Exp}(\beta)$ is the exponentiated beta, or the proportional odds ratio, which assesses the effect of the variable for any of the comparison categories, are the same regardless of where the intercept is made [43]. In ordinal logistic regression, an odds ratio $>1$ leads to an increase in the level or category of the response variable, whereas an odds ratio $<1$ leads to a decrease in the level or category of the response variable [44]. The odds ratio of the "social or status image" was 2.203. This means that a one-unit increase in the "social or status image" variable increased the level of fast-fashion consumer adoption 2.203 times. Similarly, a one-unit increase in the "uniqueness" variable increased the level of fast-fashion consumer adoption 1.733 times. As a result, the innovation level of consumer adoption groups, which is a categorical variable, can be strongly explained by these two motivations.

\section{CONCLUSIONS}

Fast fashion consumption is still the driving mechanism in the fashion market. To our knowledge, this study is the first to categorize the fast-fashion consumers concerning the adoption of innovation, analyze their perceptions of fast-fashion, and model the relationship between the consumer groups and their motivations for adoption.

The categorization of the fast-fashion consumers on the basis of innovativeness revealed a shift from Roger's adoption curve. The first three consumer adoption groups, which are innovators, early adopters, and early majority, covered more of the population when compared to the percentages of the population covered by the same categories in Rogers' adoption curve; the sudden appearance and the shorter life cycle of fastfashion products can be suggested as the possible reason for such a shift. The curve illustrating the fast-fashion cycle and innovation adoption would be beneficial for the retailers for better predicting their sales and profitability corresponding to different products.
One of the most important findings of the study has been to reveal the differences in the fast-fashion perception of each consumer adoption group. Further, the relationships prevailing between the categorical levels of consumer adoption and the motivations of adoption were modeled. These findings provide retailers a means to identify actions to improve their responsiveness to consumer demands. Consumers in different adoption groups have varying needs in terms of perceptions and motivations. Resultantly, cultivating a detailed understanding of the differences between such narrow consumer groups can help retailers to develop target-specific marketing strategies.

Furthermore, the method described in this study may contribute significantly to the literature and may guide professionals acting in the fast-fashion business; and the method deployed in the present study is also capable of being expanded in further studies to include an examination of the precise reasons pursuant to which the fast-fashion consumer groups differ in their perceptions and behaviors, such as brand and shopping channel preferences.

Recently, the fast-fashion concept has begun to include the sustainability aspect; thus, future research could be directed toward the evaluation of fast-fashion consumption, consumers' perceptions, and the motivations that underlie adoption and purchase of fast-fashion products within a sustainabilityincluded framework.

\section{References}

[1] Global Fast Fashion Market Report (2020 to 2030) - COVID-19 Growth and Change (2020). Retrieved: February 11, 2021. Web site: https://www.globenewswire. com/news-release/2020/06/09/2045523/0/en/Global-FastFashion-Market-Report-2020-to-2030-COVID-19-Growthand-Change.html

[2] Baghi, I., Gabrielli, V., Codeluppi, V. (2013). Consumption practices of fast fashion products: A consumer-based approach. Journal of Fashion Marketing and Management: An International Journal, 17(2), 206-224.

[3] Zarley, M. (2007). An exploratory investigation of the decision processes and psychographic characteristics of fast versus slow fashion consumers, Doctoral dissertation, Colorado State University, USA.

[4] Joy, A., Sherry, J. F., Venkatesh, A., Wang, J., Chan, R. (2012). Fast fashion, sustainability, and the ethical appeal of luxury brands. Fashion Theory, 16(3), 273-295.

[5] Rogersü, E. M. (1995). Diffusion of innovations. Simon and Schuster (New York).

[6] Ronald, G., Leisa, R. F. (1992). Identifying innovators in consumer product markets. European Journal of Marketing, 26(12), 42-55.

[7] Rogers, E. M. (1983). Diffusion of innovations. Collier Macmillan (New York: Free Press; London).

[8] Saricam, C., Erdumlu, N. (2016). Modeling and analysis of the motivations of fast fashion consumers in relation to innovativeness. Autex Research Journal, 16(4), 205-213.

[9] Workman, J. E., Johnson, K. K. (1993). Fashion opinion leadership, fashion innovativeness, and need for variety. Clothing and Textiles Research Journal, 11(3), 60-64. 
[10] Baumgarten, S. A. (1975). The innovative communicator in the diffusion process. Journal of Marketing Research, 12(1), 12-18.

[11] Hirschman, E. C., Adcock, W. O. (1978). An examination of innovative communicators, opinion leaders, and innovators for men's fashion apparel. In Hunt, K., Abor, A. (Ed.), Advances in Consumer Research, Volume 05, eds, Association for Consumer Research, (Michigan).

[12] Workman, J. E., Lee, S. H. (2017). What do we know about fashion adoption groups? A proposal and test of a model of fashion adoption. International Journal of Consumer Studies, 41(1), 61-69.

[13] Workman, J. E., Caldwell, L. F. (2007). Centrality of visual product aesthetics, tactile and uniqueness needs of fashion consumers. International Journal of consumer studies, 31(6), 589-596.

[14] Davis, L. L. (1987). Consumer use of label information in ratings of clothing quality and clothing fashionability. Clothing and Textiles Research Journal, 6(1), 8-14.

[15] Stanforth, N. (1995). Fashion innovators, sensation seekers, and clothing individualists. Perceptual and Motor skills, 81(3_suppl), 1203-1210.

[16] Studak, C. M., Workman, J. E. (2004). Fashion groups, gender, and boredom proneness. International Journal of Consumer Studies, 28(1), 66-74.

[17] Bertrandias, L., Goldsmith, R. E. (2006). Some psychological motivations for fashion opinion leadership and fashion opinion seeking. Journal of Fashion Marketing and Management, 10(1), 25-40.

[18] Schrank, H. L., Lois Gilmore, D. (1973). Correlates of fashion leadership: Implications for fashion process theory. Sociological Quarterly, 14(4), 534-543.

[19] Cholachatpinyo, A., Padgett, I., Crocker, M., Fletcher, B. (2002). A conceptual model of the fashion processpart 2: An empirical investigation of the micro-subjective level. Journal of Fashion Marketing and Management: An International Journal, 6(1), 24-34.

[20] Jordaan, Y., Simpson, M. N. (2006). Consumer innovativeness among females in specific fashion stores in the Menlyn shopping centre. Journal of Consumer Sciences, 34(1), 32-40.

[21] Goldsmith, R. E., Hofacker, C. F. (1991). Measuring consumer innovativeness. Journal of the Academy of Marketing Science, 19(3), 209-221.

[22] Venter, M., Chinomona, R., Chuchu, T. (2016). Factors influencing fashion adoption among the youth in Johannesburg, South Africa. Journal of Economics and Behavioral Studies, 8(4), 92-108.

[23] Workman, J. E., Kidd, L. K. (2000). Use of the need for uniqueness scale to characterize fashion consumer groups. Clothing and Textiles Research Journal, 18(4), 227-236.

[24] Byun, S. E., Sternquist, B. (2011). Fast fashion and in-store hoarding: The drivers, moderator, and consequences. Clothing and Textiles Research Journal, 29(3), 187-201.

[25] Barnes, L. (2008). Fast consumers. In Proceedings of 86th Textile Institute World Conference, The Textile Institute, Hong Kong pp. 18-21.
[26] Aksu, M., Pektaş, G. Ö. E., Karaboğa, K. (2011). Concepts of fast fashion and artificial scarcity in marketing in the 21th century: Tchibo example. Journal of Naval Science and Engineering, 7(1), 48-70.

[27] Eastman, J. K., Goldsmith, R. E., Flynn, L. R. (1999). Status consumption in consumer behavior: Scale development and validation. Journal of Marketing Theory and Practice, 7(3), 41-51.

[28] Tian, K. T., Bearden, W. O., Hunter, G. L. (2001). Consumers' need for uniqueness: Scale development and validation. Journal of Consumer Research, 28(1), 50-66.

[29] Lawson, C., Montgomery, D. C. (2006). Logistic regression analysis of customer satisfaction data. Quality and Reliability Engineering International, 22(8), 971-984.

[30] IBM SPSS Statistics Guides, http://www.norusis.com/pdf/ ASPC_v13.pdf

[31] Hosmer, D. W., Lemeshow S. (2000). Applied logistic regression, John Wiley \& Sons Inc.(Canada).

[32] Yang, H. C., Chen, C. Y., Chen, C. W., Chen, T. H. (2008). Estimation of internal wave reflection in a two-layer fluid system by cumulative logistic regression model. Journal of Marine Science and Technology, 16(1), 44-51.

[33] Dunn, O. J., Clark, V. A. (2001). Basic statistics: A primer for the biomedical sciences (3rd ed.) John Wiley \& Sons (New York).

[34] Howell, D. C. (2002). Statistical methods for psychology (5th ed.)., Duxbury/Thomson Learning (Pacific Grove).

[35] Rosenthal, J. A. (2001). Statistics and data interpretation for the helping professions. CA: Brooks/Cole Thomson Learning (Belmont).

[36] Darden, W. R., Reynolds, F. D. (1972). Predicting opinion leadership for men's apparel fashions. Journal of Marketing Research, 9(3), 324-328.

[37] Zhang, B., Kim, J. H. (2013). Luxury fashion consumption in China: Factors affecting attitude and purchase intent. Journal of Retailing and Consumer Services, 20(1), 68-79.

[38] Goldsmith, R. E., Moore, M. A., Beaudoin, P. (1999). Fashion innovativeness and self-concept: $A$ replication. Journal of Product \& Brand Management, 8(1), 7-18.

[39] Barnes, L., Lea-Greenwood, G., Watson, M. Z., Yan, R. N. (2013). An exploratory study of the decision processes of fast versus slow fashion consumers. Journal of Fashion Marketing and Management, 17(2), 141-159.

[40] Bagwell, L. S., Bernheim, B. D. (1996). Veblen effects in a theory of conspicuous consumption. The American Economic Review, 86(30), 346-373.

[41] Muzinich, N., Pecotich, A., Putrevu, S. (2003). A model of the antecedents and consequents of female fashion innovativeness. Journal of Retailing and Consumer Services, 10(5), 297-310.

[42] Tabachnick, B. G., Fidell, L. S., Ullman, J. B. (2007). Using multivariate statistics (Vol. 5), Pearson (Boston).

[43] Kleinbaum, D. G., Dietz, K., Gail, M., Klein, M., Klein, M. (2002). Logistic regression: A self learning text, Springer (New York).

[44] Field, A. (2009). Discovering statistics using SPSS (and sex and drugs and rock ' $n$ ' roll) (3rd ed.). UK: Sage (London). 